\title{
Effects of Green Tea Supplementation on Elements, Total Antioxidants, Lipids, and Glucose Values in the Serum of Obese Patients
}

\author{
Joanna Suliburska • Pawel Bogdanski • \\ Monika Szulinska • Marta Stepien • \\ Danuta Pupek-Musialik • Anna Jablecka
}

Received: 31 January 2012 / Accepted: 3 May 2012/Published online: 15 May 2012

(C) The Author(s) 2012. This article is published with open access at Springerlink.com

\begin{abstract}
The consumption of green tea has been associated with cardiovascular and metabolic diseases. There have been some studies on the influence of green tea on the mineral status of obese subjects, but they have not yielded conclusive results. The aim of the present study is to examine the effects of green tea extract on the mineral, body mass, lipid profile, glucose, and antioxidant status of obese patients. A randomized, double-blind, placebo-controlled study was conducted. Forty-six obese patients were randomly assigned to receive either $379 \mathrm{mg}$ of green tea extract, or a placebo, daily for 3 months. At baseline, and after 3 months of treatment, the anthropometric parameters, blood pressure, and total antioxidant status were assessed, as were the levels of plasma lipids, glucose, calcium, magnesium, iron, zinc, and copper. We found that 3 months of green tea extract supplementation resulted in decreases in body mass index, waist circumference, and levels of total cholesterol, lowdensity cholesterol, and triglyceride. Increases in total antioxidant level and in zinc concentration in serum were also observed. Glucose and iron levels were lower in the green
\end{abstract}

\footnotetext{
J. Suliburska $(\bowtie)$

Department of Human Nutrition and Hygiene,

Poznan University of Life Sciences,

Wojska Polskiego 31 Str.,

60-624, Poznan, Poland

e-mail: jsulibur@up.poznan.pl Poznan, Poland

A. Jablecka

Department of Clinical Pharmacology,

Poznan University of Medical Sciences,

Poznan, Poland
}

P. Bogdanski • M. Szulinska • M. Stepien • D. Pupek-Musialik Department of Internal Medicine, Metabolic Disorders and Hypertension, Poznan University of Medical Sciences, tea extract group than in the control, although HDLcholesterol and magnesium were higher in the green tea extract group than in the placebo group. At baseline, a positive correlation was found between calcium and body mass index, as was a negative correlation between copper and triglycerides. After 3 months, a positive correlation between iron and body mass index and between magnesium and HDL-cholesterol, as well as a negative correlation between magnesium and glucose, were observed. The present findings demonstrate that green tea influences the body's mineral status. Moreover, the results of this study confirm the beneficial effects of green tea extract supplementation on body mass index, lipid profile, and total antioxidant status in patients with obesity.

Keywords Obesity $\cdot$ Green tea $\cdot$ Polyphenol epigallocatechin-3-gallate $\cdot$ Minerals $\cdot$ Oxidative stress . Lipid · Glucose

\section{Introduction}

Overweight and obesity represent rapidly growing threats to the health of populations in an increasing numbers of countries worldwide. The adverse health consequences associated with obesity include cardiovascular disease, type 2 diabetes, hypertension, dyslipidemia, cancers, and respiratory problems. Increasing evidence shows that obesity is associated with insulin resistance, with chronic low-grade inflammatory responses, and with oxidative stress $[1,2]$.

Oxidative stress consists of unbalanced higher cellular levels of reactive oxygen species (ROS), e.g., superoxide and hydroxyl radicals and cellular antioxidant defense [3]. The generation of ROS is ubiquitous, since such species are 
generated during aerobic metabolism, i.e., during mitochondrial and glycated protein oxidations. Blood may be vulnerable to oxidative stress induced by diabetes and may become exposed to ROS continuously generated by the auto-oxidation of hemoglobin and polyunsaturated fatty acids (PUFAs) [4, 5]. Because of their high rate of oxygen consumption, their high content of PUFAs, and their poor enzymatic antioxidant defense, blood cells exhibit increased vulnerability to diabetes-induced oxidative stress $[4,5]$. Lipid peroxidation (LP) causes injury to cells and to intracellular membranes and may lead to cell damage and subsequently to cell death [6]. In order to scavenge ROS, various enzymatic and nonenzymatic antioxidant defense systems exist in the blood [7].

Moreover, many of the metabolic imbalances involved in obesity (e.g., glycemic, lipidemic) give rise to organ dysfunction and accelerated aging processes [8]. Several studies show obesity-related abnormalities in mineral status. The association between overweight, obesity, $\mathrm{Fe}$, calcium $\mathrm{Ca}$, and $\mathrm{Zn}$ deficiency has been observed in clinical and epidemiological studies [9]. Several studies suggest that Ca may play a role in the regulation of abdominal fat mass in obese people [10].

Understanding these pathological processes is crucial for better prevention and treatment of patients with obesity. The possible use of so-called functional food in this group of patients is particularly intriguing.

In recent years, researchers throughout the world have been investigating the potential benefits of green tea (GT) and its most abundant catechin, polyphenol epigallocatechin-3-gallate (EGCG). The positive effects of GT supplementation have been observed particularly in the prevention and control of type 2 diabetes [11]. In recent years, there have been a number of trials in humans showing the favorable effects of GT supplementation on body weight and body composition [12]. GT also has positive effects in the prevention and treatment of cardiovascular diseases [13]. Human studies suggest that GT may contribute to a reduction in the risk of atherosclerosis and cancer, as well as to the promotion of anti-hypertensive effects, body-weight control, antibacterial effects, increases in bone-mineral density, anti-fibrotic properties, and neuroprotective power [14]. There is growing evidence showing the possibility of using GT in the prevention and treatment of obesity and coexisting diseases $[11,15]$.

Several reports have focused on the interactions of polyphenols with metal ions, e.g., $\mathrm{Zn}$ and $\mathrm{Fe}$, and have suggested their possible influence on mineral distribution in the body $[16,17]$. There are few studies on the effects of GT on mineral status. The small number of studies evaluating green tea extract's (GTE) influence on mineral status in obese patients have shown inconclusive results.
The aim of our study was to estimate the influence of a 3month oral supplementation of GTE on serum concentrations of minerals, on body mass, on total antioxidant status, on the lipid profile, and on glucose concentration in obese patients.

\section{Materials and Methods}

\section{Study Patients}

Informed consent was obtained from all subjects, and the study was approved by the Research Ethics Committee of Poznan University of Medical Sciences (approval number 38/11). The research conformed to all the ethical requirements of the Helsinki declaration.

Among 145 registered patients with obesity screened at our outpatient clinic, a total of 46 (23 men, 23 women) were enrolled. The inclusion criteria were: age 30-60 years, body mass index $(\mathrm{BMI}) \geq 30 \mathrm{~kg} / \mathrm{m}^{2}$, stable body weight (less than $3 \mathrm{~kg}$ of self-reported change during the previous 3 months). The exclusion criteria were hypertension; diabetes; impaired glucose tolerance; a current need for pharmacological treatment; a history of coronary artery disease, stroke (including transient ischemic attack), congestive heart failure, or malignancy; a history of use of any dietary supplements within 3 months prior the study; abnormal liver, kidney or thyroid gland function; clinically significant inflammatory processes within the respiratory, digestive, or genitourinary tract, or in the oral cavity, pharynx, or paranasal sinuses; a history of infection in the month prior to the study; and any other condition that in the opinion of the investigator would make participation not in the best interest of the subject, or could prevent, limit, or confound the protocol-specified efficacy assessments.

\section{Study Design}

A prospective, randomized, double-blind design was applied. Randomization was performed by an independent statistician. Both patients and investigators were blinded to randomization.

All patients were randomized to receive green tea extract (Olimp Labs, Poland) at one capsule per day, or a placebo, with the morning meal for 3 months. One capsule contains $379 \mathrm{mg}$ green tea extract and $208 \mathrm{mg}$ of EGCG. The quantity of minerals in one capsule of the supplement is shown in Table 1. On the basis of the level of minerals in the supplement, it can be concluded that the daily intake of minerals from green tea extract was negligible. The placebo consisted of pure microcrystalline cellulose. All subjects were instructed to maintain an isocaloric diet and to continue their previous eating habits during the study. Subjects did 
Table 1 The amount of minerals in green tea extract

\begin{tabular}{lllll}
\hline $\mathrm{Ca}$ & $\mathrm{Mg}$ & $\mathrm{Fe}$ & $\mathrm{Zn}$ & $\mathrm{Cu}$ \\
\hline$\mu \mathrm{g} / \mathrm{g}$ & & & & \\
$\begin{array}{l}61.12 \pm 8.28 \\
\mu \mathrm{g} / \mathrm{one} \mathrm{capsule}\end{array}$ & $1098.04 \pm 148.3$ & $5.67 \pm 0.34$ & $1.81 \pm 0.32$ & $0.51 \pm 0.17$ \\
\begin{tabular}{l}
$23.22 \pm 3.42$ \\
\hline
\end{tabular} & $416.24 \pm 56.3$ & $2.15 \pm 0.06$ & $0.68 \pm 0.11$ & $0.19 \pm 0.03$ \\
\hline
\end{tabular}

not change their diet or physical activity during the study. The exercise and daily eating regimes were comparable in both groups.

At the baseline, and again after 3 months of treatment, the anthropometric parameters, blood pressure measurement, and other laboratory tests were performed on both groups.

\section{Anthropometric and Blood Pressure Measurements}

Anthropometric measurements were conducted with patients wearing light clothing and no shoes. Weight was measured to the nearest $0.1 \mathrm{~kg}$, and height to the nearest $0.5 \mathrm{~cm}$. The BMI was calculated as weight divided by height squared (kilogram per square meter). Obesity was defined as $\mathrm{BMI} \geq 30 \mathrm{~kg} / \mathrm{m}^{2}$.

Resting seated blood pressure was measured three times, and an average value was calculated according to the guidelines of the European Society of Hypertension. Regular or large adult cuffs were used, depending on the patient's arm circumference.

\section{Biochemical Measurements}

All participants had blood collected from a forearm vein in serum-separated tubes (without using an anticoagulant). The coagulated blood was left to clot at room temperature for $30 \mathrm{~min}$, and then centrifuged for $15 \mathrm{~min}$ at 2,000 r.p.m. at $4^{\circ}$ C. The supernatant fluid was then separated. Blood samples were collected after an overnight fast and after $30 \mathrm{~min}$ in the supine position. Serum samples were stored at $-20^{\circ} \mathrm{C}$ for no longer than 2-3 days.

The iron, copper, zinc, calcium, and magnesium content in the serum was determined by flame atomic absorption spectrometry (AAS-3 spectrometer, Carl Zeiss, Germany with deuterium background correction). In order to obtain the concentrations of the serum bioelements, the samples were diluted ( $v / v 1: 1)$ as follows: for $\mathrm{Fe}, \mathrm{Zn}$, and $\mathrm{Cu}$ analyses, $0.01 \%$ Triton X-100 (Merck) was used, while for the $\mathrm{Mg}$ and $\mathrm{Ca}$ analysis, aqueous solutions consisting of $0.01 \%$ Triton X-100 (Merck) and $0.05 \%$ lanthanum chloride (Merck) were used. The content of $\mathrm{Fe}, \mathrm{Cu}, \mathrm{Zn}, \mathrm{Ca}$, and $\mathrm{Mg}$ in serum and urine samples was determined at the following wavelengths: $248.3 \mathrm{~nm}(\mathrm{Fe}), 324.8 \mathrm{~nm}(\mathrm{Cu})$,
$213.9 \mathrm{~nm}(\mathrm{Zn}), 422.7 \mathrm{~nm}(\mathrm{Ca})$, and $285.2 \mathrm{~nm}(\mathrm{Mg})$. The accuracy of the method was verified by certified reference material (HUM ASY CONTROL 2 and URN ASY CONTROL 2, Randox) and reached $95 \%, 99 \%, 94 \%, 99 \%$, and $102 \%$ for $\mathrm{Ca}, \mathrm{Mg}, \mathrm{Fe}, \mathrm{Zn}$, and $\mathrm{Cu}$, respectively.

Plasma total cholesterol (TC), high-density lipoprotein (HDL), triglycerides (TG), and fasting glucose were measured using commercial kits. Serum levels of lipids were assayed in the central laboratory of Poznan University Hospital. Low-density lipoprotein cholesterol (LDL-C) was calculated using Friedewald's formula. Levels of blood glucose were determined by the routine enzymatic method.

The accuracy and precision of the techniques used to assay the lipids and glucose were validated. Reproducibility was checked with control human serum. Accuracy was assessed through the recovery value and it ranges between $95 \%$ and $109 \%$ and the variability coefficient, as an indicator of method precision, did not exceed $10 \%$.

Total antioxidant status (TAS) was established with a Randox kit (Randox laboratories, Crumlin, UK). This method is based on ABTS (2.2 azinobis 3-ethybenzthiazolinesulfate) incubation with metmyoglobin, and $\mathrm{H}_{2} \mathrm{O}_{2}$ with eventual ABTS-derived radical formation. This radical has a stable blue-green color at a wave length of $600 \mathrm{~nm}$. Antioxidants present in the sample weaken the color intensity in proportion to their concentration. Initial absorbance was recorded, and then after $3 \mathrm{~min}$, was recorded again for each sample using a Specord M-40 Carl-Zeiss Jena spectrophotometer (SPECORD M40, Carl Zeiss Jena, Germany).

\section{Statistical Analysis}

Detailed statistical analysis was performed using Statistica for Windows. The normality of the variables' distribution was verified using Shapiro-Wilk's test of normality. A logarithmic transformation was used to normalize nonnormally distributed dependent variables. Mean values, standard deviation, and median were calculated. Baseline characteristics of biochemical and demographic variables and blood pressure values were compared for the GTE and placebo groups, using the standard $t$ test for two groups. Paired $t$ tests were utilized to examine within-group differences at baseline and after 3 months. The level of statistical significance was set to $p<0.05$.

\section{Results}

Forty-six out of 145 obese patients with hypertension screened at our outpatient clinic fulfilled the inclusion and exclusion criteria and were allocated equally into the GTE and placebo groups. 
The baseline characteristics of both groups are shown in Table 2, partly in Table 3, and in Figs. 1 and 2. There were no statistically significant differences $(p>0.05)$ between the two groups prior to the study.

\section{Between-Group Comparison after 3-Month Treatment}

We found markedly lower levels of TC $(p<0.01)$, TG $(p<0.01)$, and LDL $(p=0.02)$ in the GTE group than in the control group after GTE treatment (Table 3, Figs. 1 and 2). Compared to the placebo group, BMI and waist circumference values significant decreased (respectively, $p=0.03$ and $p=0.04$ ) in GTE group after 3-month treatment (Table 3). TAS and Zn levels were markedly higher (respectively, $p<0.01$ and $p=0.03)$ in the GTE group than in placebo group (Tables 3 and 4). No differences were found in the levels of glucose, HDL, blood pressure, or in the rest of the measured minerals between groups after treatment.

\section{Within-Group Comparison after 3-Month Treatment}

Compared to the baseline measurements, 3-month treatment with GTE resulted in a change in the measured parameters only in the GTE group. GTE treatment caused significant reduction in TC and TG (respectively, $p=0.034$ and $p=0.042)$ (Figs. 1 and 2), LDL $(p=0.035)$, glucose $(p=0.043), \mathrm{Fe}(p=0.048)$, and significant increase in HDL $(p=0.044)$, TAS $(p=0.036), \mathrm{Zn}(p=0.037)$, and $\mathrm{Mg}$ $(p=0.047)$ - see Tables 3 and 4.

\section{Correlation}

A significant positive correlation between $\mathrm{Ca}$ and $\mathrm{BMI}(p=$ 0.042 ), and a negative correlation between $\mathrm{Cu}$ and TG ( $p=$ 0.038 ) were observed before treatment. After the 3-month supplementation, significant positive correlations between $\mathrm{Fe}$ and BMI $(p=0.023)$, and between $\mathrm{Mg}$ and HDL cholesterol $(p=0.023)$ were found, as was a significant negative correlation between $\mathrm{Mg}$ and glucose $(p=0.002)$ (Table 5).

\section{Discussion}

The significant influence demonstrated in our study of a 3-month GTE supplementation on mineral levels in obese patients is a new finding. Moreover, the favorable effect of GTE supplementation on body mass, lipid profile, glucose, and antioxidant status was also demonstrated.

The potential of green tea as a natural agent of weight loss has been investigated in some other studies similar to our own $[18,19]$. Some authors suggest that the polyphenolic components of green tea have an anti-obesogenic effect on fat homeostasis, by increasing thermogenesis, reducing fat absorption, and introducing modifications in appetite $[20,21]$. The results obtained (significant differences in BMI between the GTE group and the placebo group, and the slight reduction in BMI in the group with GTE) support the possible role of green tea in weight loss.

A number of experimental studies have been conducted to examine the effects of GT on carbohydrate metabolism and lipid profile $[15,19,22]$. Wu et al. [15] demonstrated that during 12-week GT supplementation, insulin sensitivity in Sprague-Dawley rats increased. They concluded that the most active component in GT is polyphenol.

Abnormalities of lipid metabolism are one of the major risk factors for the development of cardiovascular disease, very often associated with obesity. The outcomes of our study show that a 3-month supplementation exerts a positive effect on lipid profile in patients with obesity. Decreases in TC, LDL, and TG concentration were observed, along with increases in HDL concentration (within the study group). The positive effect of GT in human studies has also been observed by others $[19,23]$. The results could be partly caused by the decreased absorption of cholesterol and glucose from the diet in the presence of the polyphenols from GTE in the small intestine, especially if the supplement is taken by subjects during meals [24]. GT catechins influence micellar solubility, luminal lipid hydrolysis, and intestinal lipid absorption, and they may interfere with the emulsification, hydrolysis, and micellar solubilization of lipids, suggesting that the cholesterol-lowering effect of catechins

Table 2 Baseline characteristic of both groups

\begin{tabular}{lccc}
\hline Gender (male/female) & GTE group $(n=23)$ & $\begin{array}{l}\text { Placebo }(n=23) \\
12 / 11\end{array}$ & NS \\
\hline Age (years) & $11 / 12$ & $52.26 \pm 7.71$ & NS \\
Time since diagnosis of obesity (years) & $48.56 \pm 8.81$ & $8.35 \pm 2.85$ & NS \\
BMI (kg/m ${ }^{2}$ ) & $9.70 \pm 2.30$ & $33.45 \pm 2.65$ & NS \\
Waist circumference $(\mathrm{cm})$ & $32.07 \pm 2.41$ & $104.98 \pm 6.35$ & $\mathrm{NS}$ \\
\hline
\end{tabular}

Comparison of GTE and placebo group with unpaired $t$ test

Data are mean $\pm \mathrm{SD}$; mean the arithmetic mean; $S D$ standard deviation, $n$ number of subjects, GTE green tea extract, BMI body mass index, NS not significant, $p$ level of significance 
Table 3 Within-group anthropometric, blood pressure, and biochemical data at baseline and after 3 months of treatment

\begin{tabular}{|c|c|c|c|c|c|c|}
\hline \multirow[t]{2}{*}{ Variables } & \multicolumn{3}{|l|}{ Baseline } & \multicolumn{3}{|l|}{ After 3 months } \\
\hline & $\begin{array}{l}\text { GTE group } \\
(n=23)\end{array}$ & $\begin{array}{r}\text { Placebo } \\
(n=23)\end{array}$ & $p$ & $\begin{array}{l}\text { GTE group } \\
(n=23)\end{array}$ & $\begin{array}{l}\text { Placebo } \\
(n=23)\end{array}$ & $p$ \\
\hline BMI $\left(\mathrm{kg} / \mathrm{m}^{2}\right)$ & $32.07 \pm 2.41$ & $33.45 \pm 2.65$ & NS & $31.71 \pm 2.29$ & $33.36 \pm 2.66$ & 0.03 \\
\hline $\begin{array}{l}\text { Waist circumference } \\
(\mathrm{cm}) \mathrm{SBP}(\mathrm{mmHg})\end{array}$ & $\begin{array}{l}101.78 \pm 6.42 \\
130.72 \pm 6.95\end{array}$ & $\begin{array}{l}104.98 \pm 6.53 \\
129.58 \pm 7.88\end{array}$ & NS NS & $\begin{array}{l}101.15 \pm 6.42 \\
128.15 \pm 6.86\end{array}$ & $\begin{array}{l}105.02 \pm 6.10 \\
128.32 \pm 6.16\end{array}$ & $0.04 \mathrm{NS}$ \\
\hline DBP $(\mathrm{mmHg})$ & $85.10 \pm 12.47$ & $84.21 \pm 3.32$ & NS & $84.06 \pm 12.26$ & $84.50 \pm 3.86$ & NS \\
\hline LDL (mmol/L) & $3.44 \pm 1.03$ & $3.80 \pm 1.19$ & NS & $3.02 \pm 0.96^{*}$ & $3.71 \pm 1.12$ & 0.02 \\
\hline HDL (mmol/L) & $1.12 \pm 0.24$ & $1.09 \pm 0.25$ & NS & $1.28 \pm 0.26^{*}$ & $1.15 \pm 0.21$ & NS \\
\hline Glucose (mmol/L) & $5.64 \pm 0.44$ & $5.67 \pm 0.44$ & NS & $5.48 \pm 0.31 *$ & $5.59 \pm 0.43$ & NS \\
\hline TAS (mmol/L) & $1.91 \pm 0.23$ & $1.90 \pm 0.15$ & NS & $2.09 \pm 0.28^{*}$ & $1.91 \pm 0.13$ & $<0.01$ \\
\hline
\end{tabular}

Data are mean $\pm \mathrm{SD}$; the arithmetic mean; $S D$ standard deviation, $n$ number of subjects; ${ }^{*} p<0.05$ from baseline to the end of treatment with paired $t$ test

GTE green tea extract, $B M I$ body mass index, $S B P$ systolic blood pressure, $D B P$ diastolic blood pressure, $L D L$ LDL cholesterol concentration, $H D L$ HDL cholesterol concentration, TAS total antioxidant status, $N S$ not significant, $p$ level of significance

may, at least in part, be mediated by their influence on intestinal lipid absorption $[25,26]$.

We found a beneficial influence of GTE on oxidative stress. An increase in TAS levels in the serum was observed after supplementation. Tea catechins eliminate reactive oxygen and nitric radicals, and also act as chelators of metal ions active in the system redox. Both radicals and active metal ions are highly toxic because of their destructive effect on lipids, proteins, and nucleic acid. They also interact to indirectly influence the inhibition of pro-oxidative enzymes, such as nitric oxide synthetase, lipooxygenase, cyclooxygenase, and xanthine oxidase $[27,28]$.

A literature review shows that the effect of GTE on mineral status has not been widely studied, and the present study shows novel results on this topic.

In our study, a decreased Fe level in the serum of obese patients supplemented with GTE was observed. This lower

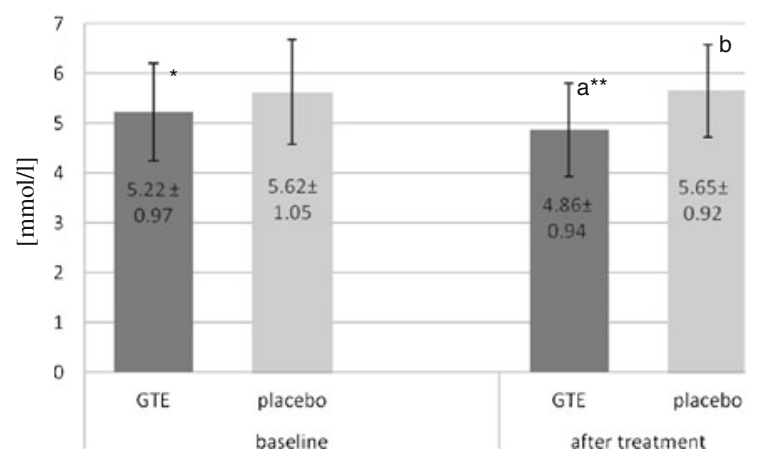
$*, * * *$ significantly differences $(\mathrm{p}<0.05)$ within group from baseline to the end of treatment
a,b significantly differences $(\mathrm{p}<0.01)$ between GTE and placebo groups

Fig. 1 Concentration of total cholesterol (millimole per liter) in serum at baseline and after 3 months of treatment. ${ }^{*},{ }^{* *}$ Significant differences $(p<0.05)$ within group from baseline to the end of treatment. ${ }^{\mathrm{a}, \mathrm{b}}$ Significant differences $(p<0.01)$ between GTE and placebo groups level of Fe in serum after treatment may be caused by the low availability of this mineral, as suggested by Zeyuan et al. [29]. In their experiment on rats, they found that GT and its water extract inhibited the absorption of $\mathrm{Ca}, \mathrm{Fe}$, and $\mathrm{Zn}$, and promoted absorption of $\mathrm{Cu}$. In particular, the polyphenols contained in GT chelate Fe and might cause it to be less well absorbed, leading to a lower concentration in the body $[17,30]$. On the basis of our results, it can be concluded that GT supplementation may reduce the level of $\mathrm{Fe}$ in the blood of obese people, and thereby increase the deficit of this mineral in the body.

Moreover, in our study, an association was found between the concentration of $\mathrm{Fe}$ in serum and the BMI of patients after the 3-month treatment. Some authors have suggested that the alternation of Fe biomarkers in the obese population could be a result of obesity-related inflammation or of related comorbidities. Obesity has been reported to

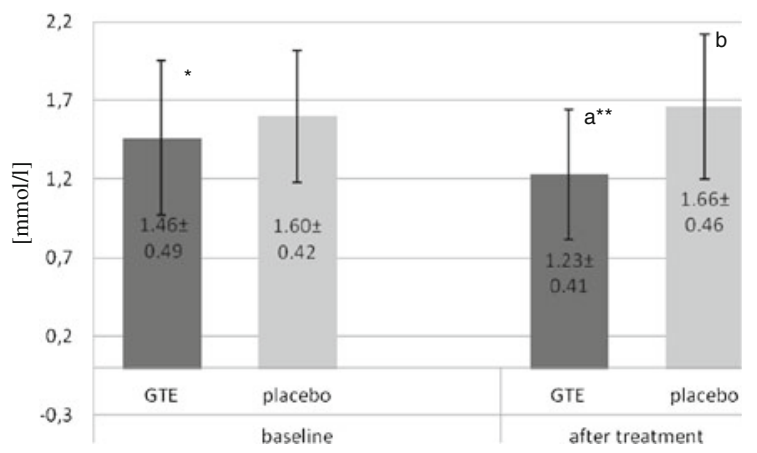

*,** significantly differences $(\mathrm{p}<0.05)$ within group from baseline to the end of treatment
a,b significantly differences $(\mathrm{p}<0.01)$ between GTE and placebo groups

Fig. 2 Concentration of triglycerides (millimole per liter) in serum at baseline and after 3 months of treatment. ${ }^{*}{ }^{* *}$ Significant differences $(p<0.05)$ within group from baseline to the end of treatment. ${ }^{\mathrm{a}, \mathrm{b}}$ Significant differences $(p<0.01)$ between GTE and placebo groups 
Table 4 Within-group minerals concentration in serum at baseline and after 3 months of treatment

\begin{tabular}{|c|c|c|c|c|c|c|}
\hline \multirow[t]{2}{*}{ Variables } & \multicolumn{3}{|l|}{ Baseline } & \multicolumn{3}{|c|}{ After 3 months } \\
\hline & $\begin{array}{l}\text { GTE group } \\
(n=23)\end{array}$ & $\begin{array}{l}\text { Placebo } \\
(n=23)\end{array}$ & $p$ & $\begin{array}{l}\text { GTE group } \\
(n=23)\end{array}$ & $\begin{array}{l}\text { Placebo } \\
(n=23)\end{array}$ & $p$ \\
\hline $\mathrm{Fe}(\mu \mathrm{mol} / \mathrm{l})$ & $17.91 \pm 2.20$ & $17.28 \pm 3.16$ & NS & $16.02 \pm 3.19^{*}$ & $16.91 \pm 2.97$ & NS \\
\hline $\mathrm{Zn}(\mu \mathrm{mol} / \mathrm{l})$ & $12.09 \pm 2.12$ & $12.45 \pm 3.11$ & NS & $14.08 \pm 3.16^{*}$ & $13.01 \pm 2.98$ & $<0.05$ \\
\hline $\mathrm{Cu}(\mu \mathrm{mol} / \mathrm{l})$ & $13.97 \pm 3.12$ & $14.30 \pm 2.13$ & NS & $13.82 \pm 2.98$ & $14.45 \pm 3.17$ & NS \\
\hline $\mathrm{Ca}(\mathrm{mmol} / \mathrm{l})$ & $2.72 \pm 0.59$ & $2.75 \pm 0.63$ & NS & $2.92 \pm 0.92$ & $2.98 \pm 0.69$ & NS \\
\hline $\mathrm{Mg}(\mathrm{mmol} / \mathrm{l})$ & $0.97 \pm 0.52$ & $1.05 \pm 0.76$ & NS & $1.07 \pm 0.68 *$ & $1.09 \pm 0.43$ & NS \\
\hline
\end{tabular}

Data are mean $\pm \mathrm{SD}$; the arithmetic mean; $S D$ standard deviation, $n$ number of subjects; ${ }^{*} p<0.05$ from baseline to the end of treatment with paired $t$ test

GTE green tea extract, NS not significant, $p$ level of significance

induce an inflammatory state, and some studies have suggested that inflammation contributes to high serum Fe levels in obese subjects [31]. In this study, the reduction in BMI index was associated with a decrease in inflammation biomarkers (unpublished data) and in the serum Fe level.

As with other authors, we found that GT treatment reduced Fe status and improved $\mathrm{Zn}$ and $\mathrm{Mg}$ status in patients and experimental animals [16, 17]. The increased $\mathrm{Zn}$ level in the serum may be associated with improved antioxidant status subsequent to GT treatment, as concluded by Hamdaoui et al. [16].

We have also observed an association between glucose and $\mathrm{Mg}$, which confirms the results of other studies [32,33]. In this study, we observed following supplementation that there were increased concentrations of $\mathrm{Mg}$ associated with decreased levels of glucose in the serum of the GTE group. It may be suggested that higher levels of $\mathrm{Mg}$ in the body led to a reduction in plasma glucose and stabilized the glucose level during treatment. Soltani et al. [34] concluded that $\mathrm{Mg}$ could improve the structure of the pancreas (especially in diabetic individuals) and may prevent morphological changes of blood vessels. In this study, the improvement in Mg status after GTE supplementation was associated with higher levels of HDL cholesterol in the serum of patients. A positive correlation between $\mathrm{Mg}$ in serum and HDL has also

Table 5 Significant correlation between minerals and other parameters in GTE group

$r$, Pearson's correlation coefficient; $p$, level of significance

\begin{tabular}{lll}
\hline Minerals & Parameters & $r ; p$ \\
\hline Baseline & & \\
$\mathrm{Ca}$ & $\mathrm{BMI}$ & $0.33 ; 0.042$ \\
$\mathrm{Cu}$ & $\mathrm{TG}$ & $-0.34 ; 0.038$ \\
$\mathrm{After}$ & treatment & \\
$\mathrm{Fe}$ & $\mathrm{BMI}$ & $0.37 ; 0.023$ \\
$\mathrm{Mg}$ & glucose & $-0.48 ; 0.002$ \\
$\mathrm{Mg}$ & HDL & $0.32 ; 0.023$ \\
\hline
\end{tabular}

been observed by other authors [35]. The results obtained in experimental and clinical studies suggest the higher $\mathrm{Mg}$ levels in the body are associated with a beneficial effect on lipid profile [36, 37].

In this study, we did not find any change in Ca levels of serum during GTE treatment. Other studies have shown that supplementation with GT polyphenols results in an increase in bone-mineral density and a decrease in urinary calcium levels $[38,39]$. In this study, we did not evaluate the concentration of this mineral in other tissues, such as bones. The lack of effect of GTE supplementation on serum Ca levels in patients in this study may be due to factors of homeostasis in the bodies of the subjects during treatment.

Moreover, at the baseline of the study, we observed a negative correlation between $\mathrm{Cu}$ and TG levels in serum. A similar association between $\mathrm{Cu}$ and $\mathrm{TG}$ in the serum of obese patients with hypertension was found in our previous study [40], and has also been observed by others [41]. These results confirm the association between $\mathrm{Cu}$ status and lipid profile in the body.

It is also worth noting that prior to the treatment, the patients' BMI was positively correlated with the concentration of $\mathrm{Ca}$ in serum. This result may be connected with the role of $\mathrm{Ca}$ in the regulation of abdominal fat mass in obese people [10].

\section{Conclusions}

The present findings demonstrate strong evidence for the effect of GTE on the mineral status of obese people. Our results suggest that GT improves the status of $\mathrm{Zn}$ and $\mathrm{Mg}$ in such individuals. However, supplementation with GT can deepen the deficit of Fe which is observed in obesity. Moreover, this study confirms the beneficial influence of GTE supplementation on body mass, lipid profile, glucose, and TAS in obese patients. As the subjects represented in the 
studied group are overrepresented in the modern population, the potential advantages of GTE should be carefully evaluated. Further studies on a larger scale and with a longer time of observation are needed to support our data.

\section{Conflict of Interest None}

Open Access This article is distributed under the terms of the Creative Commons Attribution License which permits any use, distribution, and reproduction in any medium, provided the original author(s) and the source are credited.

\section{References}

1. Stelzer I, Zelzer S, Raggam RB, Prüller F, Truschnig-Wilders M, Meinitzer A, Schnedl WJ, Horejsi R, Möller R, Weghuber D, Reeves G, Postolache TT, Mangge H (2012) Link between leptin and interleukin- 6 levels in the initial phase of obesity related inflammation. Transl Res 159(2):118-124

2. Gupta D, Krueger CB, Lastra G (2012) Over-nutrition, obesity and insulin resistance in the development of $\beta$ cell dysfunction. Curr Diabetes Rev 10(8(1))

3. Kovacic P, Somanathan R (2008) Unifying mechanism for eye toxicity: electron transfer, reactive oxygen species, antioxidant benefits, cell signaling and cell membranes. Cell Membr Free Radic Res 2:56-69

4. Cay M, Naziroglu M, Simsek H, Aydilek N, Aksakal M, Demirci M (2001) Effects of intraperitoneally administered vitamin $C$ on antioxidative defense mechanism in rats with diabetes induced by streptozotocin. Res Exp Med Berl 200:205-213

5. Naziroglu M, Cay M (2001) Protective role of intraperitoneally administered vitamin $\mathrm{E}$ and selenium on the antioxidative defense mechanisms in rats with diabetes induced by streptozotocin. Biol Trace Elem Res 79:149-159

6. Naziroglu M (2009) Role of selenium on calcium signaling and oxidative stress-induced molecular pathways in epilepsy. Neurochem Res 34:2181-2191

7. Cimen MY (2008) Free radical metabolism in human erythrocytes. Clin Chim Acta 390:1-11

8. Tzanetakou IP, Katsilambros NL, Benetos A, Mikhailidis DP, Perrea DN (2012) Is obesity linked to aging? Adipose tissue and the role of telomeres. Ageing Res Rev 11(2):220-229

9. de Luis DA, Pacheco D, Izaola O, Terroba MC, Cuellar L, Cabezas G (2011) Micronutrient status in morbidly obese women before bariatric surgery. Surg Obes Relat Dis. doi:10.1016/ j.soard.2011.09.015

10. Rosenblum JL, Castro VM, Moore CE, Kaplan LM (2012) Calcium and vitamin D supplementation is associated with decreased abdominal visceral adipose tissue in overweight and obese adults. Am J Clin Nutr 95(1):101-108

11. Harrison D, Guzik T, Lob H, Madhur M, Marvar P, Thabet S, Vinh A, Weyand C (2011) Inflammation, immunity, and hypertension. Hypertension 57(2):132-140

12. Dona M, Dell'Aica I, Calabrese F, Benelli R, Morini M, Albini A, Garbisa S (2003) Neutrophil restraint by green tea: inhibition of inflammation, associated angiogenesis, and pulmonary fibrosis. J Immunol 170:4335-4341

13. Kuriyama S, Shimazu T, Ohmori K, Kikuchi N, Nakaya N, Nishino Y, Tsubono Y, Tsuji I (2006) Green tea consumption and mortality due to cardiovascular disease, cancer, and all causes in Japan: the Ohsaki study. JAMA 296:1255-1265

14. Cabrera C, Artacho R, Giménez R (2006) Beneficial effects of green tea-a review. J Am Coll Nutr 25(2):79-99

15. Wu LY, Juan CC, Ho LT, Hsu YP, Hwang LS (2004) Effect of green tea supplementation on insulin sensitivity in Sprague-Dawley rats. J Agric Food Chem 52:643-648

16. Hamdaoui MH, Chahed A, Ellouze-Chabchoub S, Marouani N, Ben Abid Z, Hédhili A (2005) Effect of green tea decoction on long-term iron, zinc and selenium status of rats. Ann Nutr Metab 49(2):118-124

17. Record IR, McInerney JK, Dreosti IE (1996) Black tea, green tea, and tea polyphenols. Effects on trace element status in weanling rats. Biol Trace Elem Res 53(1-3):27-43

18. Wang H, Wen Y, Du Y, Yan X, Guo H, Rycroft JA, Boon N, Kovacs EM, Mela DJ (2010) Effects of catechin enriched green tea on body composition. Obesity (Silver Spring) 18(4):773-779

19. Basu A, Sanchez K, Leyva MJ, Wu M, Betts NM, Aston CE, Lyons TJ (2010) Green tea supplementation affects body weight, lipids, and lipid peroxidation in obese subjects with metabolic syndrome. J Am Coll Nutr 29(1):31-40

20. Thavanesan $N$ (2011) The putative effects of green tea on body fat: an evaluation of the evidence and a review of the potential mechanisms. Br J Nutr 106(9):1297-1309

21. Rains TM, Agarwal S, Maki KC (2011) Antiobesity effects of green tea catechins: a mechanistic review. J Nutr Biochem 22(1):1-7

22. Brown LA, Lane J, Coverly J, Stocks J, Jackson J, Stephen A, Bluck L, Coward A, Hendrickx H (2009) Effects of dietary supplementation with the green tea polyphenol epigallocatechin-3gallate on insulin resistance and associated metabolic risk factor: randomized controlled trial. Br J Nutr 101(6):886-894

23. Batista Gde A, Cuhna CL, Scartezini M, Von der Heyde R, Bitencourt MG, Melo SF (2009) Prospective double-blind crossover study of Camellia sinensis (green tea) in dyslipidemias. Arg Bras Cardiol 93(2):128-134

24. Frejnagel S, Wroblewska M (2010) Comparative effect of green tea, chokeberry and honeysuckle polyphenols on nutrients and mineral absorption and digestibility in rats. Ann Nutr Metab 56:163-169

25. Koo SI, Noh SK (2007) Green tea as inhibitor of the intestinal absorption of lipids: potential mechanism for its lipid-lowering effect. J Nutr Biochem 18(3):179-183

26. Shishikura Y, Khokhar S, Murray BS (2006) Effects of tea polyphenols on emulsification of olive oil in a small intestine model system. J Agric Food Chem 54(5):1906-1913

27. Ahn HY, Kim CH (2011) Epigallocatechin-3-gallate regulates inducible nitric oxide synthase expression in human umbilical vein endothelial cells. Lab Anim Res 27(2):85-90

28. Tayama Y, Sugihara K, Sanoh S, Miyake K, Morita S, Kitamura S, Ohta S (2011) Effect of tea beverages on aldehyde oxidase activity. Drug Metab Pharmacokinet 26(1):94-101

29. Zeyuan D, Bingying T, Xiaolin L, Jinming H, Yifeng C (1998) Effect of green tea and black tea on the metabolisms of mineral elements in old rats. Biol Trace Elem Res 65(1):75-86

30. Thephinlap C, Ounjaijean S, Khansuwan U, Fucharoen S, Porter JB, Srichairatanakool S (2007) Epigallocatechin-3-gallate and epicatechin-3-gallate from green tea decrease plasma non-transferrin bound iron and erythrocyte oxidative stress. Med Chem 3(3):289-296

31. Yanoff LB, Menzie CM, Denkinger B, Sebring NG, McHugh T, Remaley AT, Yanovski JA (2007) Inflammation and iron deficiency in the hypoferremia of obesity. Int J Obes (Lond) 31(9):1412-1419

32. Sales CH, Pedrosa LF, Lima JG, Lemos TM, Colli C (2011) Influence of magnesium status and magnesium intake on the blood glucose control in patients with type 2 diabetes. Clin Nutr 30(3):359-364

33. Song CH, Song IK, Ju SY, Ock SM (2011) Serum magnesium level is negatively associated with fasting serum glucose level in Korean adults. Biol Trace Elem Res 143(2):612-618 
34. Soltani N, Keshavarz M, Minaii B, Mirershadi F, Asl SZ, Dehpour AR (2005) Effects of administration of oral magnesium on plasma glucose and pathological changes in the aorta and pancreas of diabetic rats. Clin Exp Pharm Physiol 32:604-610

35. Ansari MR, Maheshwari N, Shaikh MA, Laghari MS, Darshana LK, Ahmed K (2012) Correlation of serum magnesium with dyslipidemia in patients on maintenance hemodialysis. Saudi J Kidney Dis Transpl 23(1):21-25

36. Hadjistavri LS, Sarafidis PA, Georgianos PI, Tziolas IM, Aroditis CP, Hitoglou-Makedou A, Zebekakis PE, Pikilidou MI, Lasaridis AN (2010) Beneficial effects of oral magnesium supplementation on insulin sensitivity and serum lipid profile. Med Sci Monit 16(6): CR307-CR312

37. Randell EW, Mathews M, Gadag V, Zhang H, Sun G (2008) Relationship between serum magnesium values, lipids and anthropometric risk factors. Atherosclerosis 196(1):413-419
38. Shen CL, Wang P, Guerrieri J, Yeh JK, Wang JS (2008) Protective effect of green tea polyphenols on bone loss in middle-aged female rats. Osteoporos Int 19:979-990

39. Shen CL, Chyu MC, Yeh JK, Zhang Y, Pence BC, Felton CK, Brismée JM, Arjmandi BH, Doctolero S, Wang JS (2011) Effect of green tea and Tai Chi on bone health in postmenopausal osteopenic women: a 6-month randomized placebo-controlled trial. Osteoporos Int. doi:10.1007/s00198-011-1731-x

40. Suliburska J, Bogdański P, Pupek-Musialik D, Krejpcio Z (2011) Dietary intake and serum and hair concentrations of minerals and their relationship with serum lipids and glucose levels in hypertensive and obese patients with insulin resistance. Biol Trace Elem Res 139(2):137-150

41. Galhardi CM, Diniz YS, Rodrigues HG, Faine LA, Burneiko RC, Ribas BO, Novelli EL (2005) Beneficial effects of dietary copper supplementation on serum lipids and antioxidant defenses in rats. Ann Nutr Metab 49:283-288 